\title{
Using YouTube Videos to Enhance Learner Autonomy in Writing: A Qualitative Research Design
}

\author{
Nguyen Minh Trang \\ Faculty of Foreign Languages, Binh Duong University, Vietnam
}

\begin{abstract}
YouTube videos play a vital role as powerful educational resources for language learning and cultural understanding. Using authentic YouTube videos to develop students' writing skills is not often applied, especially at tertiary level. The paper discusses the reasons YouTube should be used as inside and outside of classroom writing activities. Then the research design offers a review of literature relating to the use of YouTube videos in various fields of language education. Methods to implement the research including research tools and steps taken for data analysis are also recommended. The article ends with limitation of the use of YouTube videos and suggestions for further studies of the topic.
\end{abstract}

Index Terms-YouTube video, learn autonomy, writing activities, authentic writing

\section{INTRODUCTION}

\section{A. Textbooks Will Fade into History}

In dealing with rapid changes around the world, especially in dealing with changes of education in the $21^{\text {st }}$ century, several studies have been carried out in the use of integrating technology with language education (Shell, Gunter, \& Gunter 2010; Paulsen, 2000; Lian, 2011). For instance, Shell, Gunter, and Gunter (2010) say that traditional textbooks will fade into history as all areas of education create increasingly interactive and extensive Web- and video-enhanced digital textbooks. Many of these books will correlate to national and state curriculum standards and benchmarks (p. 501). These authors go on to say that if teachers or educators use technology in classroom, technology will bring them many benefits. For example, integrating technology into our curriculum can help students become more excited about learning. Technology reaches more students by involving a variety of learning styles, and technology allows students to construct their learning (p. 468).

Researchers also recognize that effective technology tools, strategies, and resources if tactfully used, can assist foreign language learning and teaching by motivating students in speaking another language and deeply understand another culture (Paulsen, 2000). Thanks to technology, Web-based, student-centered learning activities using authentic, meaningful, and interactive resources can help improve students' performance in the same way as learning language and culture in classroom conducted by face-to-face teaching modes.

Lian (2011) emphasizes the use of technology integration into the educational settings as he says "students, if they wish, are now able to access information from a multiplicity of highly reputable sources, not just from text books or lectures provided by their home institutions" (p. 6).

YouTube and the Integration of YouTube Videos in Language Teaching and Language Learning

YouTube (http://en.wikipedia.org/wiki/YouTube) developed by PayPal employees in 2005, and owned by Google since late 2006 is a channel in which videos are shared, uploaded or viewed. On YouTube, users can create their own videos, tag a video's content, write a title and content of the video, give their own comments or comment on other users' videos, search for videos of their interests, etc. Jones and Cuthrell (2011) consider YouTube as a Web 2.0 site which its members can use to collect information, "share their work and participate in peer feedback through asynchronous interaction with other users". This website displays a wide variety video clips, TV clips, and music videos, and amateur content such as video blogging, short original videos, and educational videos. YouTube videos has been uploaded by individuals; however, major media corporations including "CBS, the BBC, Vevo, Hulu, and other organizations offer some of their material via YouTube, as part of the YouTube partnership program. Unregistered users can watch videos, and registered users can upload an unlimited number of videos" (Brook 2011, p. 38).

Shell et al. (2010) states that integrating YouTube videos can transition our classroom to a more participatory learning environment and therefore create a place where students will want to be. It reaches more students by involving a variety of learning styles, allowing students to construct their own-paced study. In addition, students "use YouTube videos in language learning as supplementary resources for textbook materials. Students create and share their selfconstructed videos" (p. 468).

\section{B. Learner Autonomy}


For Benson (2006), autonomy is a way in which people take control over their lives. Hence, in language education, he says "autonomy in learning is about people taking more control over their learning in classrooms and outside them, and autonomy in language learning about people taking more control over the purposes for which they learn languages and the ways in which they learn them" (p. 1).

Lian (1993) also mentions the notion of autonomy in any context that implies at least:

(a) "internal evaluation" by students. That means the evaluation was done by learners of their own language usage and requirements (Holec, 1979);

(b) "learning how to learn". Importantly, students can evaluate various activities inside and outside the class. They beware of their own learning processes as well as their reactions to their learning processes. "Only then will they become conscious of what does or does not suit their learning style and so structure their learning experience accordingly"(Crawford, 1986 cited in Lian 1993, p. 4).

\section{LITERATURE REVIEW}

The last decades of the twentieth century were dominated by the evolution of the World Wide Web (www.) Although the Web will continue to evolve and mature, it is clear that the second decade of the twenty-first century will be dominated by the wireless revolution that is taking place globally. Today wireless technology represents an evolution in products and services that are quickly transforming the way people live, work, learn, and teach (Shell, Gunter, \& Gunter, 2010). When reviewing previous studies on the use of YouTube videos in classroom, the researcher of this project found out Roddt and Peier (2013) say that "the use of YouTube in education is a relatively new field of study and not much literature has been published regarding the subject." (p. 473). Furthermore, Watkins and Wilkins (2011) also recognize that aside Berk (2009)'s study, unfortunately, specific inquiry into online video use for classroom writing activities is fairly rare (p. 114).

\section{A. Research Related to YouTube Videos}

Current researches on the use of YouTube in language classrooms have been reported, ranging from different benefits that YouTube videos have brought to language education.

YouTube Videos and Learner Autonomy

In their study, Swain and Johnson (1997) have recognized the benefits of using YouTube videos in the classroom. They said that if YouTube videos are used in the classroom, learners will have a chance to be exposed to real-life English. Using YouTube videos also encourages students in autonomous learning styles. When students regularly use a wide variety of English media, they can achieve second language immersion that might not be available in their study programs. Furthermore, as Mangubhai, (2005) says the immersion of teaching and techniques will help increase the second language acquisition inputs that have generally positive effects on the language acquisition process (Watkins $\&$ Wilkins, 2011, p. 114). One good reason to emphasize on learning using digital media and technology including YouTube videos is that language learners have already been familiar with a variety of Web 2.0 technologies for diverse purposes in real-life contexts. Thus, there will be "an underlying premise that the benefits of using Web 2.0 technologies for educational purposes can foster students' self-regulated learning that positively affects their potential to attain academic success." (Kitsantas \& Dabbagh, 2011, p. 3). More recently, Wang and Chen (2020) investigate Taiwanese second language learners' self-regulated learning via English tutoring videos on the YouTube platform. In their study, L2 learners were found to benefit from YouTube videos. The authors said the videos selected for classroom use have played an important role in promoting learners' willingness to seek academic support while learning a second language.

YouTube Videos Involving Student Engagement

In their study, Roddt and Peier (2013) find out that a new aspect to teaching a course using YouTube videos in class. The videos brought "a new approach to teaching and it is believed that the use of YouTube as a teaching tool could have an effect on the level of student engagement" (p. 474). The purpose of their study is to seek new insights into the use of YouTube in education by measuring the level of student engagement in their learning with the use of YouTube and without the use of YouTube and how students felt about the use of YouTube in the classroom. The subjects of their study were students from University of Cape Town, South Africa. The research was conducted at a single point of time and the research instrument was online questionnaire. Data were quantitatively and qualitatively analyzed. Their findings were rather positive as $64 \%$ of the responds said that the designed YouTube videos from the study had engaged them at least frequently. (p. 485). For the perceptions of the students who used YouTube videos, not much information and results of the findings were made. However, the authors just concluded that the target students in their study felt that "the use of YouTube in class was successful and many of them recommended the use of videos from other courses" (p. 486).

\section{YouTube Videos Enhancing EFL Students' Content Learning}

Another research was conducted by Alwehaib (2013) entitled "The impact of using YouTube in EFL classroom on enhancing EFL students' content learning." Alwehaib carried out his study at Princess Noura Bint Abdulrahman University in Saudi Arabia. The study experimented the impact of integrating YouTube videos into EFL instruction which aimed at enhancing EFL college students' learning of the course content. To achieve the purpose of the study, 
quasi-experimental research was implemented through the use of pretest and posttest and through the researcher's observations. There were 45 students in the control group and 51 students in the experimental group. Students from the experimental group were instructed the theoretical background of the course through the use of YouTube videos and the students of the control group were taught the same content through the usual lecture-based method. Statistical procedures are used to obtain quantitative data through the use of t-test analysis. The study was done within six weeks of Term 2 of the academic year 2011. Major findings of the study yielded results favorable to use of the YouTube technology, and the author recommends that "YouTube should be considered as an effective instructional tool for enhancing content learning of EFL college students and as an important teaching resource in classroom" (p. 935).

YouTube Videos Enhancing EFL Students' Cultural Learning

Kim and Kim (2021) implemented a qualitative study to explore the role of YouTube videos for educational purposes. The participants were randomly selected from Asian international students from diverse countries such as Korea, Japan, and China in an American university located with little exposure to multicultural knowledge and skills in formal classroom settings in Korea. The study was carried out in ESL classrooms, particularly in composition writing classrooms. Students in small groups of three or four were given essays to write and they were asked to discuss, use relevant online resources to develop their writing skills. That way, according to the authors, would help the research participants "create active, meaningful, and enjoyable learning environments with students from diverse linguistic and cultural communities". (p. 5). They conclude that YouTube plays an important role in providing students with main multicultural resources that are beneficial for language learners to be aware of cultural diversity and inclusion needed in today's academic and social climate. Their findings are in line with previous research which has shown the significance of using YouTube videos for cultural understanding (Pope \& Reynolds, 1997; Pope, Reynolds, \& Mueller, 2009); Wang \& Chen, 2020; Solmaz, 2018). In addition, their findings tell us that YouTube can be used as an interactive means of communication giving the access to more cross-cultural interactions and experiences. Their findings suggest that the use of YouTube is not simply for fun. YouTube is a powerful, educational channel for all aspects of students' learning paths academically and culturally. Educational use of YouTube has the potential to "enhance and expedite the quality of education in enabling students to engage in a more participatory culture of L2 education" (Kim \& Kim, 2021, p. 12). Other researchers also recognize the role of YouTube videos in providing language learners "a participatory culture in which to develop, interact, and learn" (Chau, 2010, p. 65).

YouTube and Student Perceptions on the Use of YouTube

Alimemaj (2010) carried out her study to find out the opinions of students who had used YouTube for language learning. The objectives of her study were to understand how and to what extent, her students benefitted from YouTube for their language proficiency. Quite opposite to Watkins and Wilkins' (2011) ideas, Alimemaj thinks the use of online resources to teach language students is hardly a novel concept, and I think her idea is true as she cited Egbert (2001)'s ideas saying that several fascinating and insightful articles on the use of various websites have been written, following the rapid development of the Internet in the late 1990s although she added that "articles relating specially to the use of YouTube as input for ELF courses seem to be lacking" (Alimemaj 2010, p. 11). Alimemaj conducted her qualitative research with students at University of Vlora in Albania by the means of face-to-face interviews. However, we do not know much about her students as she did not give a detailed description of the research participants, and we do not know how the participants were selected, either. We do know from her paper that she used four questions (1) What is YouTube for you?, (2) Do you find it useful for English learning?, (3) The advantages from the use of YouTube in the process of learning the English language, and (4) Comments about the use of YouTube as a supplementary material in the classroom to ask the students. Are these four questions adequate enough for the researcher to truly understand students about the use of YouTube videos in their class? However, as she said grouping the results, the students who had attended the interviews generally felt that YouTube is a great online learning tool for them with certain reasons: YouTube videos are useful for learning a language in and out of classroom settings, YouTube videos have various types and genres of the language that help students explore the target culture in a variety of ways, and YouTube can help students develop their learning autonomy levels as it encourages students to watch videos and clips continuously.

Many other researchers also recognized the benefits of YouTube videos in developing learners' abilities in listening, speaking, reading and writing, and they suggested their conceptual ideas to enrich the literature relating to the use of YouTube videos for language learning and teaching (Alimemaj 2010; Sherer 2011; Watkins \& Wilkins 2011; Mayora 2009; Chau 2010; Kim \& Kim, 2021). In addition, Yee and Hargis (2010) even suggested the use of YouTube videos in designing video quizzes (p. 9).

\section{B. Why Use YouTube Videos?}

There are many good reasons that teachers and students should use YouTube videos in learning and teaching English. One of the reasons is that YouTube is completely free. They can download, edit and give comments on YouTube videos through YouTube video channel, or even they can create their own YouTube videos from YouTube editor tools.

In the field of language teaching, Shell, Gunter and Gunter (2010) pointed out that integrating YouTube videos can transition our classroom to a more participatory learning environment and, therefore, create a place where students will want to be (p. 468). Roddt and Peier (2013) also recognize that with the rapid development of technology, English education has used YouTube videos in classrooms, and YouTube videos brought a new approach to language teaching. The authors believe that "the use of YouTube as a teaching tool could have an effect on the level of student engagement, 
hopefully developing learner autonomy" (p. 474). Therefore, for language learners, choosing good and interesting YouTube videos is important to assist them to have a good resource to watch, learn and entertain themselves both in class and out of classroom settings. In her study, Alwehaib (2013) argues that using YouTube is not only beneficial to language learners as they are naturally exposed to different styles of authentic English, but also to the points that "learners themselves can gain greater authority and autonomy when learning via this platform." (p. 936). Also, due to the rapidly changing world and the increase of diverse population of students, education also needs changes in an effort to meet the needs of this diverse and changing net-generation student body. Web-based or YouTube videos bring the Internet to the forefront of instructional strategies in education -especially, the use of Web-based distance learning. Web-based instructional strategies offer creative solutions for homebound students, home-schooled students, at-risk students, students who are physically challenged, and teacher shortages for specialized positions. (Shell, Gunter, \& Gunter 2010, p. 502), and as Lian (1993) says if students now wish, they can gain access to information they need for their study from "a multiplicity of highly reputable sources, not just from text books or lectures provided by their home institutions" (cited in Lian et al., 1993).

\section{The Purpose of the Study}

Recognizing that YouTube videos can also play an alternative role in helping students learn English, the purpose of this study is to discover if YouTube videos when used as a tool for writing activities can assist university students develop their autonomy or not, and to what extent YouTube videos can help learners engage and develop learner autonomy. The study uses writing activities to understand learner autonomy due to the fact that "the potential of YouTube used as a writing resource in EFL literature seems to have seen overlooked” (Mayora 2009, p.1).

\section{Research Questions}

As the purpose of the study is to discover whether the use of YouTube videos has any positive effects on student engagement and student autonomous learning, the following research questions will be addressed:

1. To what extent YouTube videos help students develop their learning autonomy?

2. What are the students' perceptions of the use of YouTube videos in classroom?

\section{ReSEARCH Methodology}

This is a qualitative research design using students at college or university as the subjects of the study. The research design suggests using questionnaire, semi-structured interview, and teacher and student's diaries as research instruments YouTube videos will be carefully selected for two recommended writing activities. The following section will concretely describe the research methodology.

\section{A. Subjects}

The subjects of this research will be purposively selected up to around 60-100 students who are attending at a college or university to help the researcher understand the target subjects as much as possible recommended by Creswell (2014). The target students can be first-year students as they all have at least certain years of basic English learning at high schools. These students are from writing or composition classes where a writing textbook together with YouTube videos are used as teaching materials for this study. The number of 60-100 students is a manageable number for the researcher to gather data for data analysis recommended by Lederman and Abell (2004) and Tian (2012).

Among these students, some can be chosen from the English field of study and some can be from other area of study as this will help the researcher gain participant validation for the research credibility, hoping different students from different academics will bring out different motivations for their self-learning methods.

The students will be grouped of four or five in their already existing classroom settings to carry out writing activities using YouTube videos.

\section{B. Research Instruments}

To gain the validity and reliability of the study, data will be collected and triangulated by means of multiple sources such as semi-structured interviews, questionnaire, and teacher's or students' diaries by in-depth descriptions of the situation (Golafshani, 2003; Patton, 2002).

1. YouTube videos will be used in class as a research tool to develop learner autonomy. Videos will be carefully selected by the researcher and they are recommended to learners. As each term actually lasts only ten weeks (excluding two weeks for a mid-term test and a final examination), there will be ten YouTube videos selected and introduced to the target students. For YouTube video selection, video topics are suggested by both teachers and students. A discussion of teacher-researcher and target students on the selection of YouTube videos for writing activities will be made and a decision of which YouTube videos are chosen will be reached with the agreement of both parties. However, as the purpose of this study is to see learner autonomy development, the teacher-researcher's decision on YouTube video selection will be fallen more on students' selection side.

Each video will last approximately 15-20 minutes to make sure students feel interested in watching them. There will be two core writing activities that the students of the study are required to perform: (1) writing about the content of the video and (2) giving comments on the video. (For more details, see Appendix A: Two Main Writing Activities). Each 
group will have one group leader who helps the researcher monitor and take account of their classmates' participation in the designed writing activities using YouTube videos as a tool. All students will be encouraged to use their personal Internet or school Internet to access to YouTube videos uploaded from the researcher's website and other online YouTube video-sharing websites to perform their assigned tasks. However, as the aim of the study is to develop learner autonomy, target students can choose YouTube videos recommended by the researcher or not, it totally depends on the students' own choice. Also, students can suggest YouTube videos that they feel interested in watching and performing the writing assignment tasks.

\section{Questionnaire}

A survey questionnaire will be designed and sent to students asking them about the extent that YouTube videos help them develop their learning autonomy via the designed writing activities. Students will also be asked to express their perceptions on the use of YouTube videos in this research. All the items in the questionnaire were examined by three experts in the field of study. The questionnaire items will be validated and accepted after grammar and question ambiguity is clarified. To complete the validity process, the questionnaire will be further tested in a pilot study (John, Mohamad, Mahmud, \& Md Fuad, 2021).

\section{Semi-structured interviews}

In order to understand more about the research subjects, their ideas when doing writing with the videos, and especially their ideas about their learning autonomy, an in-depth interview is conducted to each research subject in a friendly-manner atmosphere. The interview is designed in a semi-structured format to help the informants provide as much as information about their beliefs or perceptions on the use of YouTube videos in their classes. The interviews will be tape-recorded, and field notes are also taken during the interview processes to help the researcher get clear images of things happened at the interview when transcription work is done later.

\section{Teacher and Student Diaries}

Students are encouraged to use their dairies to record the process of using YouTube videos in their learning process. Diaries reflect students' perceptions on the use of YouTube videos and the benefits or drawbacks students face when using YouTube videos as an instrument to perform their writing activities. Student diaries will be collected weekly to help their researcher record the autonomous learning processes that actually happen to the research participants within certain periods of designed research plan. Teacher's diaries are also be examined to compare the reflexivity of students' and teacher's ideas about the use of YouTube videos each week. Diaries give researchers an opportunity to study each learner's view on affective factors on their autonomy (Bailey \& Oschner, 1983; Bailey, 1991; Domyei, 2007). Bailey (1991) strongly argues that "if properly done, the diary study can provide us with important missing pieces in this incredibly complex mosaic pieces which may not fully accessible by any other means" (cited in Gkonou, 2013, p. 51).

\section{Timeline for Research Implementation}

In order to gain credibility for the study, Rallis and Rossman (2009) suggest data from a qualitative study should be gathered "over a significant period of time" because data gathered from a short period of time or in their words "superficial one-shot data collection is definitely insufficient" (p. 265). Therefore, this research should be conducted over a rather long time period. The research implementation timeline will be divided into two academic terms, each term lasts 10 weeks. Thus, the research implementation time will be divided into two phases: an initial phase and an extended phase as indicated in Table 1 below:

TABLE 1

TIMELINE FOR THIS RESEARCH IMPLEMENTATION

\begin{tabular}{|l|l|l|}
\hline Stages: & Phase 1(initial fieldwork) & Phase 2 (extended fieldwork) \\
\hline Academic School Year: & Term 1 & Term 2 \\
\hline Evaluation Phase: & Initial Evaluation & Final Evaluation \\
\hline
\end{tabular}

As the purpose of this study aims to investigate whether the use of YouTube videos will stimulate learner autonomy or not, conducting research within a rather long period of time will assist the teacher-researcher understand more about the students and gain deeper insights of the targeted participants.

\section{Validity and Reliability of Research Instruments}

Validity and reliability are the factors contributing to the success of this study. Validity of this research can be guaranteed to bring out the accuracy of the findings and reliability of the research results. Validity ensures the researcher to carry out this approach consistently (Gibbs, 2007; Yin, 2003). To gain validity and reliability for this study, the following procedures suggest to be implemented as illustrated in Table 2: 
TABLE 2

VALIDITY AND RELIABILITY OF RESEARCH INSTRUMENTS

\begin{tabular}{|l|l|}
\hline \multicolumn{1}{|c|}{ Research Instruments } & \multicolumn{1}{|c}{ Validity and Reliability } \\
\hline Questionnaire & For content validity and reliability: \\
& - Be tried out with at least two experienced teachers in questionnaire design. \\
& - Be tried out with ten students. \\
& - Cronbach's alpha $(\alpha) \geq 0.7$ will be accepted. \\
\hline Interview & -Having more than one expert in the field to code, recode the interview data, and then compare the \\
& findings for inter-rater agreement. \\
& -Thick and rich description of the interview content analysis must be done. \\
\hline Teacher and student diaries & -Content analysis \\
\hline
\end{tabular}

Data Collection and Data Analysis:

1. Writing activities based on YouTube videos to perceive learner autonomy

There are two kinds of writing activities designed to perceive students' learning autonomy.

Activity 1: Each week students will watch one YouTube video. Students are asked to discuss with their classmates on the content of each video. Discussion on the video content is done in pairs or in groups, depending on individuals' choice. After the discussion, students will gather in groups and write about the main content of the video they have watched. Their ideas about the video content are shared with other groups, and they also receive feedback from the teacher-researcher and friends to help adjust ideas and to correct mistakes they might make when writing about the video content. Finally, students upload the content of the video they have written to YouTube channel, below the online video and share video links to friends and the teacher. Good writings on the video are announced to groups, and credits will be given to the best group work as an encouragement to their achievement.

Activity 2: Another writing task is also given to the target students requiring them to watch a YouTube video and give comments on the video. Students are encouraged to choose the video that has had many comments already posted. With this task, the research students will have a good chance to discuss and criticize other people's comments before writing their own comments. Students' comments on the video are shared to students from other groups and the researcher. They will receive feedback from their classmates and the teacher. Finally, they upload their comments to YouTube video channel, right below the video they commented. Links to the video are given to other friends and the teacher as well. Student writing on video contents and giving comments of videos follow the writing process suggested by Tompkins (2008): prewriting, drafting, revising, editing and publishing.

In order to develop learner autonomy, YouTube videos selected for writing activities are recommended by the researcher based on the key topics the course curriculum requires students to take. However, topics for writing video contents and video comments are decided on the basis of student interests and their levels of understanding and levels of video difficulties. Each video chosen will be short that lasts 30-45 minutes to make it easier for students to watch and perform the writing tasks. In case a selected video is long, students can use YouTube video editor tools to cut it short.

With these two designed writing activities using YouTube videos as a tool for content reviewing and comment editing, the researcher hopes the research subjects will develop their collaborative work and critical thinking spirits, hopefully these characteristics will also help learners feel more confident in doing writing tasks later in their education career or their own lives, and develop a habit of learning and doing things by themselves using technology/YouTube as an assistant learning tool to develop their self-directed study.

2. Questionnaire

In order to evaluate the effects of YouTube videos on focus groups, a survey questionnaire asking about the effects of YouTube videos on student learning autonomy is designed and delivered to students one week before students complete their courses. The questionnaire will help the researcher identify the overall impacts of YouTube on students and their perceptions on the use of YouTube videos in their classes. A survey questionnaire can be conducted online through the use of Surveymonkey.com. The results of the questionnaire will provide the researcher with descriptive data that will be presented in charts or graphs with percentage of students' answers to the survey questionnaire.

3. Interview

A semi-structured interview will be conducted to each student (see Appendix B: Interview Questions). The in-depth interview will be used as another reflective tool to help the researcher obtain more students' feedback that the designed questionnaire fails to obtain adequate information (Nunan, 2006; Seliger \& Shohamy, 2001; Wilkinson \& Birmingham, 2003). The interview will be held in a friendly atmosphere so that the subjects can express their ideas and perceptions on the use of YouTube videos freely in their learning process as recommended by Dencomsbe (2003). Interviews will be transcribed, coded and recoded in four levels (1) initial coding, (2) focused coding, (3) axial coding and (4) theoretical conceptual coding suggested by Gibbs (2018). Hopefully, the coding process will help the researcher find out categories and themes that provide the researcher with the answers relating to the two research questions mentioned in the Research Questions section.

4. Student/Teacher Diaries

Research data from teacher and/or student diaries will be examined in content analysis. Field notes from these sources are feedbacks that help the researcher gain more insights into the nature of the research. Researcher-teachers can create a YouTube channel and post lists of recommended or compulsory videos for students to watch. Teachers can also use other simpler methods. For instance, teachers can ask students to keep their diaries in which they write down 
what videos they have watched, the link to those videos, a draft of their comments, and other relevant information. Learners can be required to "keep a diary in which they can write down which videos they have watched, which links to the selected videos, drafts of their comments after watching the videos, and other relevant information" (Mayora 2009, p. 8).

\section{E. How to Assess Learner Autonomy When Using YouTube Videos for Writing Activities}

The analysis of student engagement and development of their autonomous learning is quite tricky. Answers to survey questionnaire are analyzed, and a content analysis is conducted to find out the ideas related to the research questions. These related ideas will be categorized, and themes hope to be emerged to help the researcher gain insights of learner autonomy after using YouTube videos to do the designed writing activities.

For the conducted interview, transcription will be made. If the interview is spoken in the student's language that is not English, peer checking or "back translation" will be carried out to help the researcher avoid mistakes and subjectivity that may have the transcript. Transcription will be coded and recoded to find out the thematic labels and theoretical concepts that help the researcher have the answers to the research questions relating to what extent students develop their learning autonomy and their perceptions of the use of YouTube videos (Gibbs, 2018).

Student and teacher diaries are alternative tools that the researcher will use to add, check or confirm the students' ideas or answers from the questionnaire and the interview.

Students' ideas about their autonomous learning and perceptions on the use of YouTube videos will be tabulated to make it easier for the researcher to revisit and cite quotations during the writing up process.

Below is a summary of the instruments and strategies of data analysis that the researcher can use to investigate students on their autonomous learning and their perceptions on the use of YouTube videos to develop their self-directed learning modes.

TABLE 3

SUMMARY OF RESEARCH INSTRUMENTS AND DATA ANALYSIS USED IN THE STUDY

\begin{tabular}{|l|l|l|}
\hline \multicolumn{1}{|c|}{ Research Questions } & \multicolumn{1}{c|}{ Instruments } & \multicolumn{1}{c|}{ Data Analysis } \\
\hline $\begin{array}{l}\text { RQ\#1: In what ways the YouTube videos } \\
\text { that the researcher designed help students } \\
\text { develop learner autonomy? }\end{array}$ & $\begin{array}{l}\text {-Survey questionnaire (open-ended and five- } \\
\text { point Linkert scale questions) } \\
\text {-Interview } \\
\text {-Student and teacher diaries }\end{array}$ & $\begin{array}{l}\text {-Theoretical concepts from thematic coding } \\
\text {-Content analysis } \\
\text {-Content analysis }\end{array}$ \\
\hline $\begin{array}{l}\text { RQ\#2: What are the students' perceptions } \\
\text { of the use of YouTube videos in classroom? }\end{array}$ & $\begin{array}{l}\text {-Semi-structured interview } \\
\text {-Survey questionnaire } \\
\text {-Student and teacher diaries }\end{array}$ & $\begin{array}{l}\text {-Theoretical concepts from thematic coding } \\
\text {-Content analysis } \\
\text {-Content analysis }\end{array}$ \\
\hline
\end{tabular}

\section{SIGNIFICANCE OF STUDY}

The proposed study outlined above is intended to contribute to a better understanding of the YouTube video effects on students in their English language learning, and to provide more emphasis on video uses as a writing tool to develop learner autonomy.

By using YouTube videos for this study, the researcher hopes students can find it interesting to use YouTube videos or online videos as an alternative way to enhance their autonomous learning. If the results of the study are positive, students will develop their habit of critical thinking and self-taught learning modes through the use of online videos, or YouTube videos in particular, to give comments and write about the content of YouTube videos. With the results of the research, the researcher hopes YouTube videos will be viewed as another useful learning or teaching tool that students can use to learn English on their own pace and teachers can also make use of online materials as educational resources to help them in their teaching career as Alwehaib (2013) recommends, "Information technology has opened up prospects for rich and innovative approaches to tackle educational issues and provide solutions to the demands for learning resources" (p. 935).

\section{CONCLUSION}

Using YouTube videos in language learning, especially in writing development is not new. However, during the Covid-19 pandemic, the use of social networking for learning, including YouTube videos as educational resources should be encouraged and attract much attention by teachers delivering their lessons online to students. At tertiary level, using YouTube videos to seek useful information for university students to perform their authentic writing activities is vital which assists both teachers and language learners to have a powerful educational channel to promote students in language-learning autonomy in general, and in writing in particular. My paper mentioned that the role of textbook in future will be reduced and perhaps may be faded into history. The paper also indicated the benefits of YouTube videos as a powerful learning tool in language development in all skills of language acquisition, especially towards L2 learners in a context where they lack direct communication to native speakers of English, the use of YouTube channel with authentic videos can be an alternative way. The paper then pointed out the rationale YouTube videos should be creatively used in both inside and out-of-classroom settings. The main focus of this paper is the design using a qualitative research method with functional research instruments to investigate the responds' perception on YouTube 
videos, gather data collection and proceed data analysis. Summaries of research instruments and research validity and reliability were clearly listed.

\section{LIMITATIONS AND SUGGESTIONS FOR FUTURE STUDIES}

Selecting YouTube videos for students' writing activities is vital. If teachers choose videos which are not students' interest, motivation in students' writing performance can be prevented. Short, authentic and fascinating YouTube videos are best resources for this kind of activities (Mayora 2009; Almurashi 2016; Kim \& Kim 2021). However, learners might not be interested in posting their comments as they fear of making mistakes due to their poor English. In this case, teachers should encourage them to create their second or third drafts or ask their peers for help. This promotes collaborative learning among students as well (Mayora, 2009).

As this paper focuses on qualitative research in a view that qualitative research with multi-instrumental triangulation will help the research gain deep understandings of language learners' perceptions of YouTube videos as an educational resource to enhance learner autonomy (Leedy \& Ormrod, 2015). More research design using a quantitative or a mixed research methods can be built to investigate the relationship of students' writing activities with and without using YouTube videos that can be implemented in future studies.

The benefits of YouTube videos are clearly seen, but how to apply YouTube videos in classroom or self-taught practice needs more investigations that help minimize the disadvantages and maximize the benefits that bring good results in language learning to language learners.

\section{Appendix A. Two Main Writing Activities}

Activity 1: Content Review Writing

- Students watch a YouTube video

- Answer questions designed by teachers to get main ideas of that video

- Write draft ideas about the video content

- Post drafts on YouTube comments for other groups' feedback

- Write final drafts, upload drafts to that YouTube video comment session below the video, and give links to teachers for feedback and assessment.

Activity 2: Give Comments on YouTube videos

- Students watch a YouTube video

- Discuss the video

- Students focus on comments already posted for that video

- Discuss comments

- Write their own comments, discuss their drafts

- Peer-editing their drafts

- Post comments on that YouTube video

- Give teachers video links for feedback and assessment.

\section{APPENDIX B. INTERVIEW QUESTIONS}

The aims of these interview questions are to gain:

1. Student reflection on their learning autonomy

2. Student perceptions on the use of YouTube videos in the learning process.

- Do you think YouTube videos are useful for English learning?

- How are YouTube videos useful for your writing activities?

- What are the advantages and disadvantages of using of YouTube videos in your language learning?

- Comment on the use of YouTube videos as a supplementary writing material in your class.

Note: The interview focuses mainly on these core questions, but additional questions relating to the main questions may arise and the structures of interview questions can be varied..

\section{REFERENCES}

[1] Alimemaj, Z. (2010). YouTube, language learning and teaching techniques. The Magazine of Global English Speaking Higher Education. 15(3), 10-12. Retrieved October 3, 2021 from https://files.eric.ed.gov/fulltext/EJ1061416.pdf

[2] Almurashi, W. A. (2016). The effective use of YouTube videos for teaching English language in classrooms as supplementary material at Taibah University in Alula. International Journal of English Language and Linguistics Research. Vol.4, No.3, pp.32-47. Retrieved September 25, 2021 from https://www.eajournals.org/wp-content/uploads/The-Effective-Use-of-YoutubeVideos-for-Teaching-English-Language-in-Classrooms-as-Supplementary-Material-at-Taibah-University-in-Alula.pdf

[3] Alwehaib, H. (2013). The impact of using YouTube in EFL classroom on enhancing EFL students' content learning. Retrieved September 25, 2021 from https://files.eric.ed.gov/fulltext/EJ1061416.pdf 
[4] Bailey, K. M. (1983). Competitiveness and Anxiety in Adult Second Language Learning: Looking At and Through the Diary Studies. In 11.W. Seliger and MR. Long (eds.), Classroom Oriented Research in Second Language Acquisition. Rowley, Mass: Newsbury House, pp. 67-103.

[5] Bailey, K. M. (1990). The Use of Diary Studies in Teacher Education Programs. In J.C. Richards and D. Nunan (eds.), Second Language Teacher Education. Cambridge: Cambridge University Press, pp. 215-226.

[6] Baker, W., \& Sangiamchit, C. (2019). Transcultural communication: Language, communication and culture through English as a lingua franca in a social network community. Language and Intercultural Communication, 19, 471-487. Retrieved August 10 , 2021 from https://eprints.soton.ac.uk/430257/

[7] Benson, P. (2006) Autonomy in Language Learning. Retrieved August 8, 2021 from http: www.ec.hku.hk/autonomy/what.html

[8] Berk, R. A. (2009). Multimedia teaching with video clips: TV, movies, YouTube, and mtvU in the college classroom. International Journal of Technology in Teaching and Learning. 5(1), 1-21. Retrieved May 6, 2021 from https://www.researchgate.net/publication/228349436_Multimedia_Teaching_with_Video_Clips_TV_Movies_YouTube_and_ mtvU_in_the_College_Classroom

[9] Brook, J. (2011). The Affordances of YouTube for Language Learning and Teaching. TESOL working paper series. Retrieved October $19, \quad 2021 \quad$ from http://www.hpu.edu/CHSS/LangLing/TESOL/ProfessionalDevelopment/TESOL_WPS/Archives_TESOLWPS/Vol_9_Fall111. html

[10] Chau, C. (2010). YouTube as a participatory culture. New Direction for Youth Development.128, 65-74. Retrieved August 9, 2021 Chau/b4c607365d6e39fc2999a4c43c964f7b6fd06b28

[11] Crawford, J. (1986). Lifelines -Can an Integrated Audio-Visual Course Meet Student Needs on the On-Arrival Programme?. In SGAV Review, No 10, pp.19-28.

[12] Creswell, J. W. (2014). A concise introduction to mixed methods research. SAGE publications. Los Angeles, USA.

[13] Dencomsbe, M. (2003). The good research guide: For small-scale social research projects. Maidenhead, Berkshire, England: Open University Press.

[14] Dornyei, Z. (2007). Research Methods in Applied Linguistics. Oxford: Oxford University Press.

[15] Gibbs, G. R. (2007). Analyzing qualitative data. London. UK: SAGE Publishing.

[16] Gibbs, G. R. (2018). Thematic coding and categorizing. In Analyzing Qualitative Data (2 ${ }^{\text {nd }}$ Ed.). London. UK: SAGE Publishing.

[17] Gkonou, C. (2013). A diary study on the causes of English language classroom anxiety. International Journal of English Studies IJES, Vol. 13(1), pp.51-68. Retrieved August 9, 2021 from https://revistas.um.es/ijes/article/view/134681

[18] Golafshani, N. (2003). Understanding reliability and validity in qualitative research. The Qualitative Report. 8(4), 597-606. Retrieved August 10, 2021 from https://nsuworks.nova.edu/tqr/vol8/iss4/6/

[19] Holoc, H. (1979). Autonomy and Foreign Language Learning. Oxford. Pergamon Press.

[20] John, P. W., Mohamad, M., Mahmud, S. N. D., \& Md Fuad, N. I. M. (2021). The Perceptions of Tertiary Level Learners on the Use of Mobile App 'Balloon Vocabulary' in Improving Vocabulary for Reading Comprehension. Theory and Practice in Language Studies, Vol. 11, No. 9, pp. 1007-1017, September 2021. DOI: http://dx.doi.org/10.17507/tpls.1109.05

[21] Jones, T. \& Cuthrell, K. (2011). YouTube: Educational potentials and pitfalls. Computers in the Schools, 28(1), 75-85. Retrieved July 6, 2021 from https://www.tandfonline.com/doi/full/10.1080/07380569.2011.553149?needAccess=true

[22] Kim, S. \& Kim, H.-C. (2021). The Benefits of YouTube in Learning English as a Second Language: A Qualitative Investigation of Korean Freshman Students' Experiences and Perspectives in the U.S. Sustainability, 13, 7365. Retrieved September 2, 2021 from https://doi.org/10.3390/su13137365

[23] Kitsantas, A. \& Dabbagh, N. (2011). The role of web 2.0 technologies in self-regulated learning. New Directions for Teaching and Learning. 126, 99-106. Retrieved June 8, 2021 from https://ssrlsite.files.wordpress.com/2018/01/kitsantas-dabbagh-2011the-role-of-web-2-0-tech-in-srl.pdf

[24] Lederman, N. G., \& Abell, S. K. (2014). Handbook of research on science education (Vol. 2): Taylor and Francis (Routledge).

[25] Leedy, P. D. \& Ormrod, J. E. (2015). Practical Research. (11 $1^{\text {th }}$ Ed). Essex, England. Pearson

[26] Lian, A-P. (2011). Reflections on language-learning in the 21st century: The rhizome at work. RJAS Journal, Vol.1 No.1, pp. 516. $\quad$ Retrieved August $\quad 27, \quad 21$ from https://andrewlian.com/andrewlian/prowww/rangsit/FORMATTED_1PSC2nT_V1N1_Lian_APL.pdf

[27] Lian, A-P (1993). Awareness, Autonomy and Achievement. In Lian, A-P., Hoven, D. L. \& Hudson, T. J. Audio-Video Computer Enhanced Language Learning and the Development of Listening Comprehension Skills (pp. 25-41), Australian Second Language Learning Project. Retrieved August 9, 2021 from https://andrewlian.com/andrewlian/prowww/Aaa.htm

[28] Mangubhai, F. (2005). What can EFL teachers learn from immersion language teaching? Asian EFL Journal, 7 (4). pp. 203212. Retrieved September 1, 2021 from https://eprints.usq.edu.au/889/

[29] Mayora, C. (2009) Using YouTube to Encourage Authentic Writing in EFL Classrooms. TESL Reporter. 42(1), 1-12. Retrieved August 8, 2021 from https://www.academia.edu/28835789/Using_YouTube_to_Encourage_Authentic_Writing_in_EFL

[30] Nunan, D. (2006). Task-based language teaching in the Asia context: Defining 'task'. Asian EFL Journal, 8(3), 12-18. Retrieved September 17, 2021 from https://www.asian-efl-journal.com/main-editions-new/task-based-language-teaching-inthe-asia-context-defining-task/

[31] Pang, H. (2020). Is active social media involvement associated with cross-culture adaption and academic integration among boundary crossing students? International Journal of Intercultural Relations. 79, 71-81. Retrieved March 21, 2021 from https://www.sciencedirect.com/science/article/abs/pii/S0147176720301656

[32] Patton, M. Q. (2002). Qualitative Research and Evaluation Methods. (3rd ed). Sage Publications: Thousand Oaks, CA, USA.

[33] Paulsen, J., (2001). New era trends and technologies in foreign language learning. Retrieved August 3, 2021 from http://imej.wfu.edu/Articles/2001/1/05/index.asp 
[34] Pope, R. L. \& Reynolds, A. L. (1997). Student affairs core competencies: Integrating multicultural awareness, knowledge, and skills. Journal of College Student Development. 38, 266-277. Retrieved September 8, 2021 from https://www.researchgate.net/profile/Amy-Reynolds-

6/publication/234713868_Student_Affairs_Core_Competencies_Integrating_Multicultural_Awareness_Knowledge_and_Skills /links/565dbf9d08ae4988a7bcebec/Student-Affairs-Core-Competencies-Integrating-Multicultural-Awareness-Knowledge-andSkills.pdf

[35] Pope, R. L., Reynolds, A. L. \& Mueller, J. A. (2009). Looking back and moving forward: Future directions for diversity research in student affairs. Journal for College Student Development, 50, 640-658. Retrieved August 8, 2021 from https://eric.ed.gov/?id=EJ868896

[36] Pope, R. L., Reynolds, A. L. \& Mueller, J. A. (2019). Multicultural Competence in Student Affairs: Advancing Social Justice and Inclusion, 2nd ed.; Jossey-Bass: San Francisco, CA, USA.

[37] Rallis, S. F. \& Rossman, G. B. (2009). Ethics and Trustworthiness in Qualitative Research in Applied Linguistics: A Practical Introduction edited by Juanita Heigham and Robert A. Croker. Palgrave MacMillian.

[38] Roddt, S. \& Peier D. (2013). Using YouTube $\odot$ in the classroom for the net generation of students. Issues in Informing Science and Information Technology. Vol.10: 473-488. Retrieved August 8, 2021 from https://www.informingscience.org/Publications/1823?Source=\%2FJournals\%2FIISIT\%2FArticles\%3FVolume\%3D0-0

[39] Seliger, H. W., \& Shohamy, E. (2001). Second language research methods. Oxford: Oxford University Press.

[40] Shell, G.B., Gunter, G.A., \& Gunter, R. E. (2010). Teachers discovering computers. Integrating Technology and Digital Media in the Classroom. USA: COURSE TECHNOLOGY. CENGAGE Learning.

[41] Sherer, P. (2011). Using online video to support student learning and engagement. College Teaching. 59: 56-59. Retrieved July 5, 2021 from https://www.jstor.org/stable/41305109

[42] Solmaz, O. (2018). Multilingual and multimodal repertoires as part of identity management on Facebook: A case of international students. Journal of International Students, 8, 1662-1680. Retrieved June 2, 2021 from https://www.researchgate.net/publication/330161258_Multilingual_and_multimodal_repertoires_as_part_of_identity_managem ent_on_Facebook_A_case_of_international_students

[43] Swain, M. \& Johnson, K. E. (1997). Immersion education: A category within bilingual education. In Immersion Education: International Perspectives, ed. by K. E. Johnson and M. Swain, 1-16. Cambridge, UK: Cambridge University Press.

[44] Tian, X. (2012). The development of an instructional model for online task-based interactive listening for EFL learners. Unpublished Doctoral Thesis, Suranaree University of Technology, Nakhon Ratchasima, Thailand.

[45] Tompkins, G. (2008). Teaching Writing: Balancing Process and Product, $5^{\text {th }}$ ed. Pearson Prentice Hall.

[46] Watkins, K. \& Wilkins, M. (2011). Using YouTube in the EFL classroom. Language Education in Asia, 2(1), 113-119. Retrieved August 2021 https://leia.org/LEiA/LEiA\%20VOLUMES/Download/LEiA_V2_I1_2011/LEiA_V2I1 A09_Watkins_Wilkins.pdf

[47] Wang, H.-C.; Chen, C.W.-Y (2020). Learning English from Youtubers: English L2 learners' self-regulated language learning on YouTube. Innovation Language Learning and Teaching. 14, 333-346. Retrieved July 3, 2021 from https://www.tandfonline.com/doi/full/10.1080/17501229.2019.1607356

[48] Wilkinson, D., \& Birmingham, P. (2003). Using research instruments: A guide for research. London: Routledge Falmer.

[49] Yee, K. \& Hargis, J. (2010). YouTube and Video Quizzes. Turkish Online Journal of Distance Education TOJDE A, 2(11). Retrieved June 8, 2021 from https://files.eric.ed.gov/fulltext/EJ1042546.pdf

[50] Yin, R. K. (2003). Case study research: Design and methods. Thousand Oaks, California: Sage Publications.

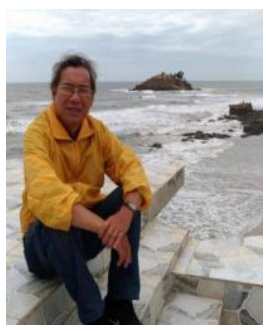

Nguyen Minh Trang holds an MA from Victoria University, Australia, and a PhD degree in TESOL from Bodhisastra University, Florida, USA. Both degrees focus on TESOL. For over 30 years of teaching English as a Foreign Languages at tertiary level, he has published articles relating to CBI issues, ELT methods, academic listening, and discourse analysis in international journals. Email: nguyenminhtrang@ hotmail.com 